\title{
Failure analysis of thermoplastic composite pipe (TCP) under combined pressure, tension and thermal gradient for an offshore riser application
}

\author{
James C. Hastie ${ }^{a, b, *}$, Maria Kashtalyan ${ }^{a, b}$, Igor A. Guz ${ }^{a, b}$ \\ a School of Engineering, University of Aberdeen, Scotland, UK \\ ${ }^{\mathrm{b}}$ Centre for Micro- and Nanomechanics (CEMINACS), UK \\ * Corresponding author. Email: r03jh15@abdn.ac.uk
}




\title{
Failure analysis of thermoplastic composite pipe (TCP) under combined pressure, tension and thermal gradient for an offshore riser application
}

Keywords: thermoplastic composite pipe; composite riser pipe; pressure gradient; thermal gradient.

\begin{abstract}
Useful characteristics of fibre-reinforced thermoplastics, including high specific strengths and moduli and excellent corrosion resistance, make them ideal candidates for offshore riser pipe applications. When in operation, risers are subjected to combined mechanical and thermal loading. In the present paper, a 3D finite element (FE) model is used to analyse stress state in a section of thermoplastic composite pipe (TCP), consisting of a fibre-reinforced thermoplastic laminate fully bonded between inner and outer thermoplastic liners, under conditions illustrative of a deepwater riser application. The effects of varying combinations of pressure and thermal differentials on the distribution of stress-based failure coefficient are examined. Failure responses under different axial tensions at low/high pressures and temperatures are assessed for configurations with different laminate ply stacking sequences. Temperature-dependent material properties are considered in the thermomechanical analysis.
\end{abstract}

\section{Introduction}

Fibre-reinforced thermoplastics are ideal candidates for subsea applications across multiple sectors, including underwater vehicles, marine construction and offshore oil and gas, due to a number of desirable characteristics including high specific strengths and moduli and excellent corrosion resistance. Historically, the use of composite materials in the offshore exploration and production (E\&P) industry has been hindered by a reluctance to use "complex" materials where traditional steels have generally proven to be fit-for-purpose. Lack of performance data, regulatory requirements, complex design procedures and repairability issues have previously been seen as factors preventing wide uptake [1]. However, as E\&P continues to extend globally into deeper waters and harsher environments the spotlight is shifting to lightweight fibre-reinforced plastic (FRP) solutions as replacements to steel. This is accelerating with the advent of industry regulatory standards and recommended practices [2-4].

Thermoplastic composite pipe (TCP) is an example of a lightweight FRP product attracting interest for offshore riser, hose and jumper applications. TCP consists of a fibre-reinforced thermoplastic laminate sandwiched between inner and outer homogeneous thermoplastic liners. The laminate serves as the main structural layer with the liners providing fluid-tightness and wear resistance. The basic construction is shown in Figure 1. A melt-fusion manufacturing process typified by leading manufacturers fully bonds the thermoplastic through all layers. TCP is produced in continuous lengths and spooled onto drums for storage, transportation and installation. 


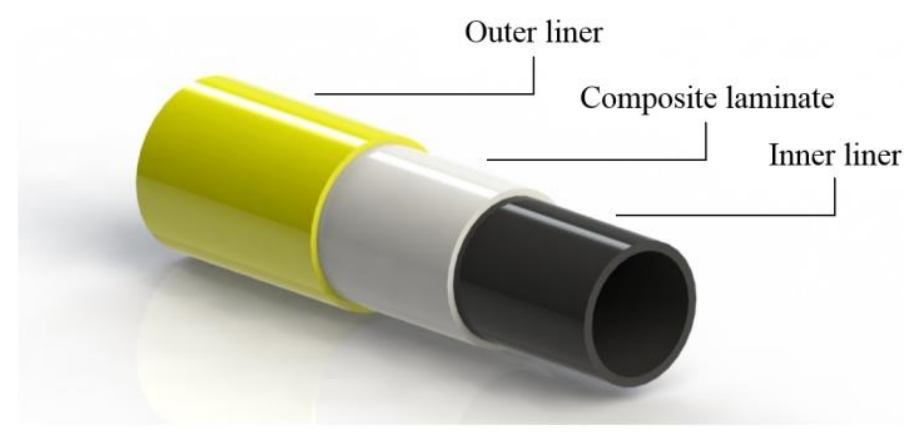

Figure 1. TCP construction

The response of spoolable fibre-reinforced tubulars under mechanical loads pertinent to offshore applications has been extensively studied (e.g. $[1,5,6])$. The behaviour of pipes specifically bearing the general TCP triple-layer structure (often referred to in different sources as 'reinforced thermoplastic pipe (RTP)') has also been the focus of recent research. Xu et al. [7] studied fibreglass TCP under tension by analytical modelling, experiments and finite element analysis (FEA). Their theoretical method, based on Knapp's cable theory [8,9], considers material nonlinearity and determines each constituent's contribution to tension resistance. Qiao et al. [10] used Knapp's theory as the basis for modelling TCP under combined tension and internal pressure. Bai et al. [11] developed a simplified theoretical model to investigate ovalisation of aramid/high-density polyethylene (HDPE) TCP under bending. Aramid fibres wound at $54.7^{\circ}$ contributed little to bending stiffness and reinforced layers were modelled as elastic-plastic HDPE with a reduction accounting for omitted fibres. The same approach was used to study TCP under combined pressure and bending [12]. Cao et al. [13] studied critical design parameters associated with pipe-lay installation of TCP, including laid depth and angle, pipeline shape and buoyant weight. Nonlinear vessel motions used in their numerical simulations were consistent with measured data. The overall development and application of TCP has been reviewed by $\mathrm{Yu}$ et al. [14]. There is a need for further analysis of complex offshore load conditions and investigations into failure mechanisms and material nonlinearity. Variations of TCP reinforced with steel wire or strip have been studied $[15,16]$. Weight added by steel can be useful for increasing stability in certain subsea piping applications.

Accounting for thermal loads is essential for accurate modelling of TCP in deepwater E\&P applications. However, literature relating to thermomechanical analysis of composite and multi-layered pipes is somewhat scarce. Relevant studies have largely been limited to analytical or semi-analytical modelling of pipes and cylinders consisting of isotropic layers [17], fibre-reinforced plies [18,19] or a sandwich arrangement of the two [20]. Uniform or gradient thermal loads have been considered in isolation or typically combined with internal pressure only. Numerical models developed using dedicated FE software would allow a wide array of mechanical and thermal load combinations to be investigated.

In the previous work [21], a 3D FE model was developed to study the effects of through-wall thermal gradient on stress-based failure of TCP under combined pressure and axial tension illustrative of a deepwater riser application. In the present paper, the developed model is used to investigate the effects of varying pressure and thermal gradient combinations on local TCP failure response. The response under different axial tensions at low/high pressures and temperatures is investigated and alternative laminate ply stacking sequences for the TCP are assessed. Temperature-dependent properties are used to define the TCP materials for thermomechanical analysis. 


\section{Problem formulation}

In this study we consider a section of TCP riser deployed in a single-leg hybrid riser (SLHR) system, illustrated in Figure 2. During operation, the section is subjected to internal and external surface pressures ( $P_{0}$ and $P_{\mathrm{a}}$ respectively), axial tension $\left(F_{\mathrm{A}}\right)$ and internal and external surface temperatures $\left(T_{0}\right.$ and $T_{\mathrm{a}}$ respectively). We define the TCP in cylindrical coordinates and consider $N$ total layers, as shown in Figure 3. Layers $k=1$ and $k=N$ are isotropic liners and the remaining layers are orthotropic plies that together form the laminate. Under axisymmetric loading, stresses and strains are independent of the hoop coordinate, $\theta$. Axial $(z)$ and radial $(r)$ displacements depend only on the corresponding directions i.e. [22]:

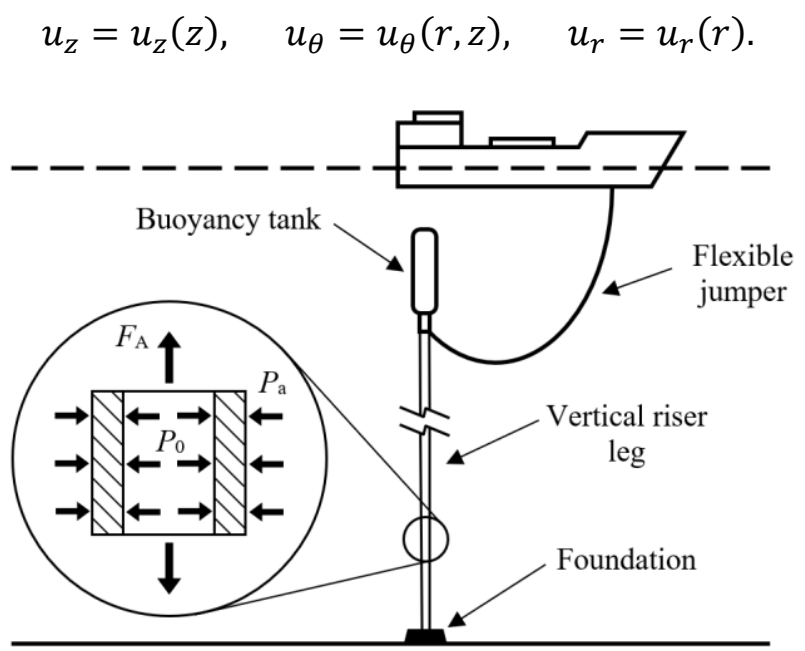

Figure 2. SLHR system

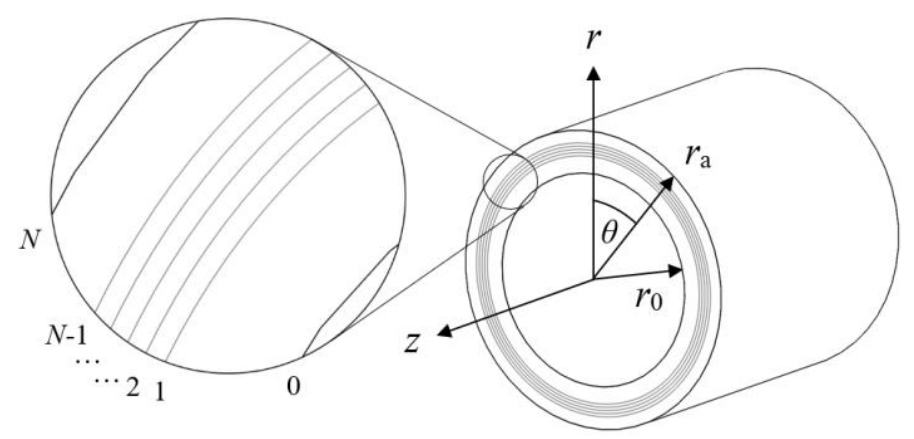

Figure 3. TCP in cylindrical coordinates

Cylindrical stresses and strains in a layer $k$ are related by the constitutive equations [23]:

$$
\left\{\begin{array}{c}
\sigma_{z} \\
\sigma_{\theta} \\
\sigma_{r} \\
\tau_{\theta r} \\
\tau_{z r} \\
\tau_{z \theta}
\end{array}\right\}=\left[\begin{array}{cccccc}
\bar{C}_{11} & \bar{C}_{12} & \bar{C}_{13} & 0 & 0 & \bar{C}_{16} \\
\bar{C}_{12} & \bar{C}_{22} & \bar{C}_{23} & 0 & 0 & \bar{C}_{26} \\
\bar{C}_{13} & \bar{C}_{23} & \bar{C}_{33} & 0 & 0 & \bar{C}_{36} \\
0 & 0 & 0 & \bar{C}_{44} & \bar{C}_{45} & 0 \\
0 & 0 & 0 & \bar{C}_{45} & \bar{C}_{55} & 0 \\
\bar{C}_{16} & \bar{C}_{26} & \bar{C}_{36} & 0 & 0 & \bar{C}_{66}
\end{array}\right\}^{(k)}\left\{\begin{array}{c}
\varepsilon_{z}-\alpha_{z} \Delta T \\
\varepsilon_{\theta}-\alpha_{\theta} \Delta T \\
\varepsilon_{r}-\alpha_{r} \Delta T \\
\gamma_{\theta r} \\
\gamma_{z r} \\
\gamma_{z \theta}-2 \alpha_{z \theta} \Delta T
\end{array}\right\}
$$

where $\bar{C}_{i j}$ are stiffness constants corresponding to a unidirectional layer orientated at angle $\varphi$ about the pipe $r$ direction as per Figure 4; $\alpha_{z}, \alpha_{\theta}, \alpha_{r}$ and $\alpha_{z \theta}$ are the cylindrical coefficients of thermal expansion (we 
note the orthotropic ply is along $z$ and $\theta$ leading to a coupling effect and non-vanishing $\left.\alpha_{z \theta}\right) ; \Delta T$ is the temperature change. The radial temperature distribution for a through-thickness thermal gradient bound by $T_{0}$ and $T_{\mathrm{a}}$ is obtained by considering steady state conduction and heat flux layer continuity, as outlined in [21].

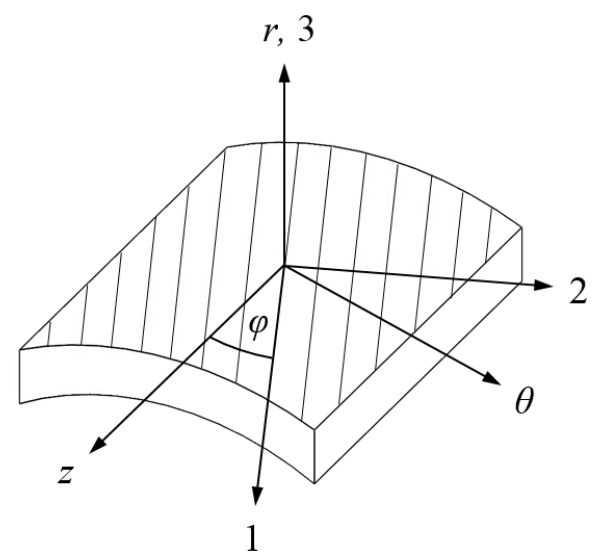

Figure 4. Orientation of unidirectional layer (material axis 1,2 and 3) with respect to cylindrical coordinates $(z, \theta, r)$

The strain-displacement relations are [22,23]

$$
\begin{gathered}
\varepsilon_{z}^{(k)}=\frac{d u_{z}^{(k)}}{d z}=\varepsilon_{0}, \quad \varepsilon_{\theta}^{(k)}=\frac{u_{r}^{(k)}}{r}, \quad \varepsilon_{r}^{(k)}=\frac{d u_{r}^{(k)}}{d r}, \\
\gamma_{\theta r}^{(k)}=\frac{d u_{\theta}^{(k)}}{d r}-\frac{u_{\theta}^{(k)}}{r}, \quad \gamma_{z r}^{(k)}=0, \quad \gamma_{z \theta}^{(k)}=\frac{d u_{\theta}^{(k)}}{d z}=\gamma_{0} r,
\end{gathered}
$$

where $\gamma_{0}$ is a pipe twist per unit length and $\varepsilon_{0}$ is constant.

The equilibrium equations for a long axisymmetric tube under prescribed loading are $[22,23]$

$$
\begin{gathered}
\frac{d \sigma_{r}^{(k)}}{d r}+\frac{\sigma_{r}^{(k)}-\sigma_{\theta}^{(k)}}{r}=0, \\
\frac{d \tau_{\theta r}^{(k)}}{d r}+\frac{2 \tau_{\theta r}^{(k)}}{r}=0, \\
\frac{d \tau_{z r}^{(k)}}{d r}+\frac{\tau_{z r}^{(k)}}{r}=0 .
\end{gathered}
$$

Combining Equations (2), (4a), (3) and (1), one obtains a second-order ordinary differential equation of which the solution for isotropic and transversely isotropic layers is [23]

$$
u_{r}^{(k)}=D^{(k)} r+E^{(k)} r^{-1}
$$

where $D^{(k)}$ and $E^{(k)}$ are unknown.

Under surface pressures, the boundary conditions at inner and outer radii are as follows [23]: 


$$
\begin{gathered}
\sigma_{r}^{(1)}\left(r_{0}\right)=-P_{0}, \quad \sigma_{r}^{(N)}\left(r_{\mathrm{a}}\right)=-P_{\mathrm{a}}, \\
\tau_{\theta r}^{(1)}\left(r_{0}\right)=\tau_{z r}^{(1)}\left(r_{0}\right)=0, \quad \tau_{\theta r}^{(N)}\left(r_{\mathrm{a}}\right)=\tau_{z r}^{(N)}\left(r_{\mathrm{a}}\right)=0 .
\end{gathered}
$$

Assuming perfectly bonded layers, the interface continuities are [22]

$$
\begin{gathered}
u_{r}^{(k)}\left(r_{k}\right)=u_{r}^{(k+1)}\left(r_{k}\right), \quad u_{\theta}^{(k)}\left(r_{k}\right)=u_{\theta}^{(k+1)}\left(r_{k}\right) \\
\sigma_{r}^{(k)}\left(r_{k}\right)=\sigma_{r}^{(k+1)}\left(r_{k}\right), \quad \tau_{\theta r}^{(k)}\left(r_{k}\right)=\tau_{\theta r}^{(k+1)}\left(r_{k}\right), \quad \tau_{z r}^{(k)}\left(r_{k}\right)=\tau_{z r}^{(k+1)}\left(r_{k}\right) .
\end{gathered}
$$

Axial equilibrium and zero torsion for a long pipe under tension are expressed as [23]

$$
\begin{aligned}
& 2 \pi \sum_{k=1}^{N} \int_{r_{k-1}}^{r_{k}} \sigma_{z}^{(k)}(r) r \mathrm{~d} r=F_{\mathrm{A}}, \\
& 2 \pi \sum_{k=1}^{N} \int_{r_{k-1}}^{r_{k}} \tau_{z \theta}^{(k)}(r) r^{2} \mathrm{~d} r=0 .
\end{aligned}
$$

Using the boundary conditions, continuity conditions and axial/torque integrals there exist $2 N+2$ unknowns, i.e. $D^{(k)}, E^{(k)}, \varepsilon_{0}$ and $\gamma_{0}$ (for $k=1,2, \ldots, N$ ), that can be solved to obtain displacements, strains and stresses from the constitutive equations.

Having obtained stresses, failure of the FRP laminate can be evaluated using the Tsai-Hill stress interactive criterion, expressed as

$$
\frac{\sigma_{1}^{2}}{X^{2}}+\frac{\sigma_{2}^{2}}{Y^{2}}+\frac{\sigma_{3}^{2}}{Z^{2}}-\sigma_{1} \sigma_{2}\left(\frac{1}{X^{2}}+\frac{1}{Y^{2}}-\frac{1}{Z^{2}}\right)-\sigma_{1} \sigma_{3}\left(\frac{1}{X^{2}}-\frac{1}{Y^{2}}+\frac{1}{Z^{2}}\right)-\sigma_{2} \sigma_{3}\left(-\frac{1}{X^{2}}+\frac{1}{Y^{2}}+\frac{1}{Z^{2}}\right)+\frac{\tau_{23}^{2}}{Q^{2}}+\frac{\tau_{13}^{2}}{R^{2}}+\frac{\tau_{12}^{2}}{S^{2}}=
$$

where $X, Y$ and $Z$ are the tensile strengths in principal directions 1,2 and 3 respectively and $Q, R$ and $S$ are the shear strengths in 23, 13 and 12 respectively. Transformation of cylindrical stresses into principal material coordinates for failure evaluation is written as

$$
\left\{\begin{array}{c}
\sigma_{1} \\
\sigma_{2} \\
\sigma_{3} \\
\tau_{23} \\
\tau_{13} \\
\tau_{12}
\end{array}\right\}=\left[\begin{array}{cccccc}
m^{2} & n^{2} & 0 & 0 & 0 & 2 m n \\
n^{2} & m^{2} & 0 & 0 & 0 & -2 m n \\
0 & 0 & 1 & 0 & 0 & 0 \\
0 & 0 & 0 & m & -n & 0 \\
0 & 0 & 0 & n & m & 0 \\
-m n & m n & 0 & 0 & 0 & m^{2}-n^{2}
\end{array}\right]\left\{\begin{array}{c}
\sigma_{z} \\
\sigma_{\theta} \\
\sigma_{r} \\
\tau_{\theta r} \\
\tau_{z r} \\
\tau_{z \theta}
\end{array}\right\}
$$

where $m=\cos \varphi$ and $n=\sin \varphi$.

Yielding of the isotropic liners can be evaluated using the well-known von Mises criterion, i.e. liner failure occurs when the von Mises stress $\left(\sigma_{\mathrm{vm}}\right)$ reaches the yield strength $\left(\sigma_{\mathrm{y}}\right)$ :

$$
\sigma_{\mathrm{vm}}=\sqrt{\frac{\left(\sigma_{1}-\sigma_{2}\right)^{2}+\left(\sigma_{2}-\sigma_{3}\right)^{2}+\left(\sigma_{3}-\sigma_{1}\right)^{2}}{2}}=\sigma_{\mathrm{y}}
$$




\section{Numerical model}

In the previous paper [21], a 3D FE model for predicting stress state in a section of TCP under combined pressure, tension and thermal gradient was developed in Abaqus/CAE and validated using an analytical solution based on the problem formulation presented in Section 2. The model is used here to study the TCP configuration in Table 1 under different combinations of pressure, tension and thermal gradients. We consider the laminate to be eight unidirectional AS4/APC-2 carbon/polyetheretherketone (PEEK) plies of equal thickness and the liners to be homogeneous APC-2 PEEK. All layers are considered perfectly bonded. APC-2 PEEK composite has a glass transition temperature $\left(T_{\mathrm{g}}\right)$ of $143^{\circ} \mathrm{C}$ and can be used in lightly loaded applications at temperatures as high as $260^{\circ} \mathrm{C}$ [24]. A comprehensive set of temperaturedependent mechanical and thermal properties compiled from literature and listed in [21] was used to define the materials over the temperature range considered in this study.

Table 1. TCP configuration

\begin{tabular}{ll}
\hline Dimension & Value \\
\hline Inner radius, $r_{0}(\mathrm{~mm})$ & 76 \\
Inner liner thickness, $t_{\text {in }}(\mathrm{mm})$ & 8 \\
Laminate thickness, $t_{\mathrm{lam}}(\mathrm{mm})$ & 8 \\
Outer liner thickness, $t_{\text {out }}(\mathrm{mm})$ & 8 \\
Outer radius, $r_{\mathrm{a}}(\mathrm{mm})$ & 100 \\
\hline
\end{tabular}

The FE model is shown in Figure 5. The full cross-section is modelled to account for off-axis orientation of fibre-reinforced plies, i.e. symmetry conditions cannot be applied to a segment model. Mechanical and thermal loads are applied simultaneously in a coupled temperature-displacement step. Internal and external pressures are applied directly on the pipe surfaces. Axial tension is applied as a point load acting on a reference point at the centre of one pipe end, fully coupled to the end face in all but the $r$ direction. A central reference point and coupling is used to fix the opposite end. On the internal surface, temperature is applied as a boundary condition. On the outer surface, a film coefficient is applied to simulate free convection to the surroundings. The model is meshed using Abaqus C3D20RT elements (20node 3D thermally coupled brick: triquadratic displacement; trilinear temperature; reduced integration).

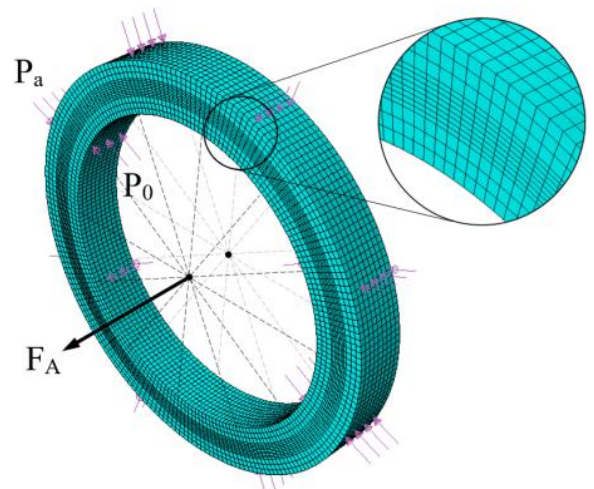

Figure 5. FE model and mechanical loading 


\section{Results and discussion}

The effects of increasing internal temperature on through-thickness failure coefficient, based on Tsai-Hill criterion for the laminate and von Mises for isotropic liners, were analysed at different internal-to-external pressure differentials for the TCP configuration in Table 1 with a typical balanced laminate ply sequence of $\left[{ }^{+55}\right]_{4}$ (eight plies with alternating orientations of $\varphi=55$ and $\left.-55^{\circ}\right)$. External pressures $\left(P_{\mathrm{a}}\right)$ of 15 and $30 \mathrm{MPa}$, corresponding to around 1,500 and $3,000 \mathrm{~m}$ ultra deepwater depths, were considered. The internal pressure was varied for $P_{0} / P_{\mathrm{a}}=1,2,3$. The internal surface temperature $\left(T_{0}\right)$ was increased from 30 to $120^{\circ} \mathrm{C}$. An axial tension of $50 \mathrm{kN}$ was applied. The surrounding ocean temperature was fixed at $4^{\circ} \mathrm{C}$ with a heat transfer coefficient of $50 \mathrm{Wm}^{-2 \circ} \mathrm{C}^{-1}$.

Failure distributions at $T_{0}=30$ and $120^{\circ} \mathrm{C}$, i.e. at low and high thermal gradients, for axial tensions of 50,250 and $500 \mathrm{kN}$ are then compared for the basic $[ \pm 55]_{4}$ laminate configuration. Two alternative configurations with $\left[( \pm 30)_{2} /( \pm 55)_{2}\right]$ and $\left[( \pm 55)_{2} /( \pm 30)_{2}\right]$ laminates are also analysed to study the benefits of having a portion of layers wound closer to the axial direction in different tension scenarios.

\subsection{Increasing internal temperature}

The effect of $T_{0}$ on through-thickness failure coefficient for $P_{0} / P_{\mathrm{a}}=1$ is shown in Figure 6 . At $P_{0}=P_{\mathrm{a}}=$ $15 \mathrm{MPa}$, the liners ( $r=76$ to $84 \mathrm{~mm} ; 92$ to $100 \mathrm{~mm}$ ) exhibit larger failure coefficient than the laminate ( $r=$ 84 to $92 \mathrm{~mm}$ ). The coefficient in the inner liner rises drastically at $r_{0}$ as $T_{0}$ is increased, whilst the coefficient through the laminate and outer liner remains fairly unchanged. At $30 \mathrm{MPa}$ the maximum failure coefficient for the TCP is observed in the laminate at low $T_{0}$. The coefficient again rises significantly with thermal gradient in the inner liner at $r_{0}$, although not to the same extent as for $15 \mathrm{MPa}$. At the higher pressure, the laminate is relatively more utilised and the level of increase in the inner liner failure coefficient with $T_{0}$ is less severe.
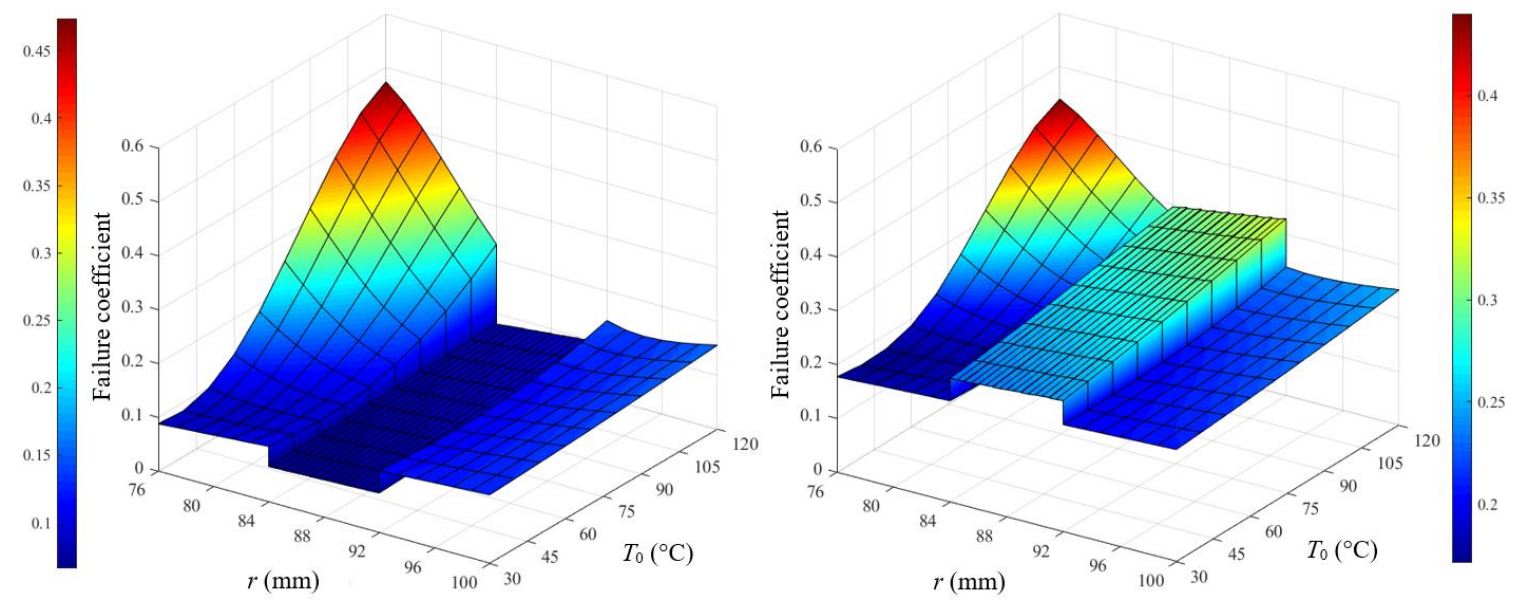

Figure 6. Effect of $T_{0}$ on failure coefficient for $P_{0} / P_{\mathrm{a}}=1: 15 \mathrm{MPa}$ (left); $30 \mathrm{MPa}$ (right)

Failure distributions for $P_{0} / P_{\mathrm{a}}=2$ are shown in Figure 7. Compared to equal $15 \mathrm{MPa}$, the inner liner failure coefficient is lower for the case of a $30 / 15 \mathrm{MPa}$ differential at higher thermal gradients but the laminate coefficient is greater. In other words, at high thermal gradient and an external pressure of $15 \mathrm{MPa}$, the liner is less prone to failure under an internal-to-external pressure ratio of two than under equal internal/external pressures as the laminate experiences greater utilisation. For the 60/30MPa scenario, large failure coefficient is exhibited in the laminate at the inner liner interface, which increases linearly 
with $T_{0}$. Unlike for $P_{0} / P_{\mathrm{a}}=1$, the von Mises coefficient in the inner liner decreases with rising $T_{0}$. Figure 8 shows the failure distributions for $P_{0} / P_{\mathrm{a}}=3$. In the case of $45 / 15 \mathrm{MPa}$ the through-thickness distribution does not change significantly with $T_{0}$ and at maximum thermal gradient the inner liner coefficient is not appreciably higher than the $30 / 15 \mathrm{MPa}$ case. Under a pressure differential of $90 / 30 \mathrm{MPa}$ the laminate coefficient increases with $T_{0}$ at the inner liner interface and the laminate is expected to fail at all $T_{0}$.
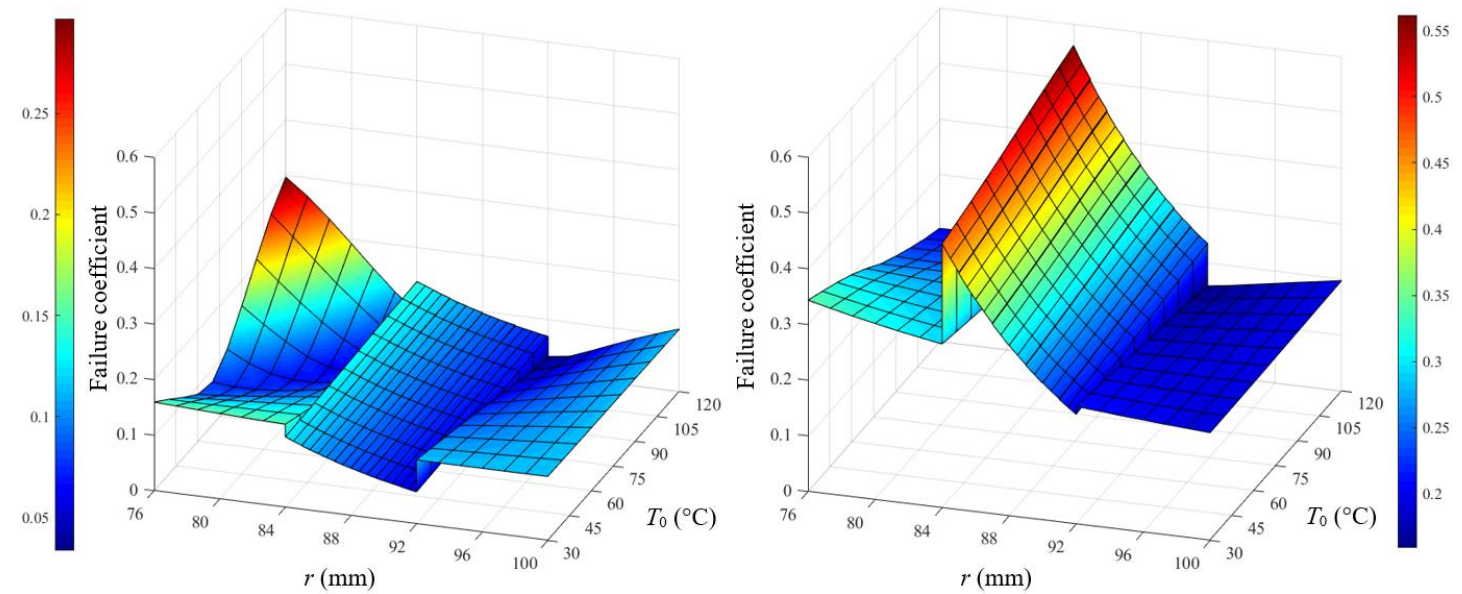

Figure 7. Effect of $T_{0}$ on failure coefficient for $P_{0} / P_{\mathrm{a}}=2: 30 / 15 \mathrm{MPa}$ (left); 60/30MPa (right)
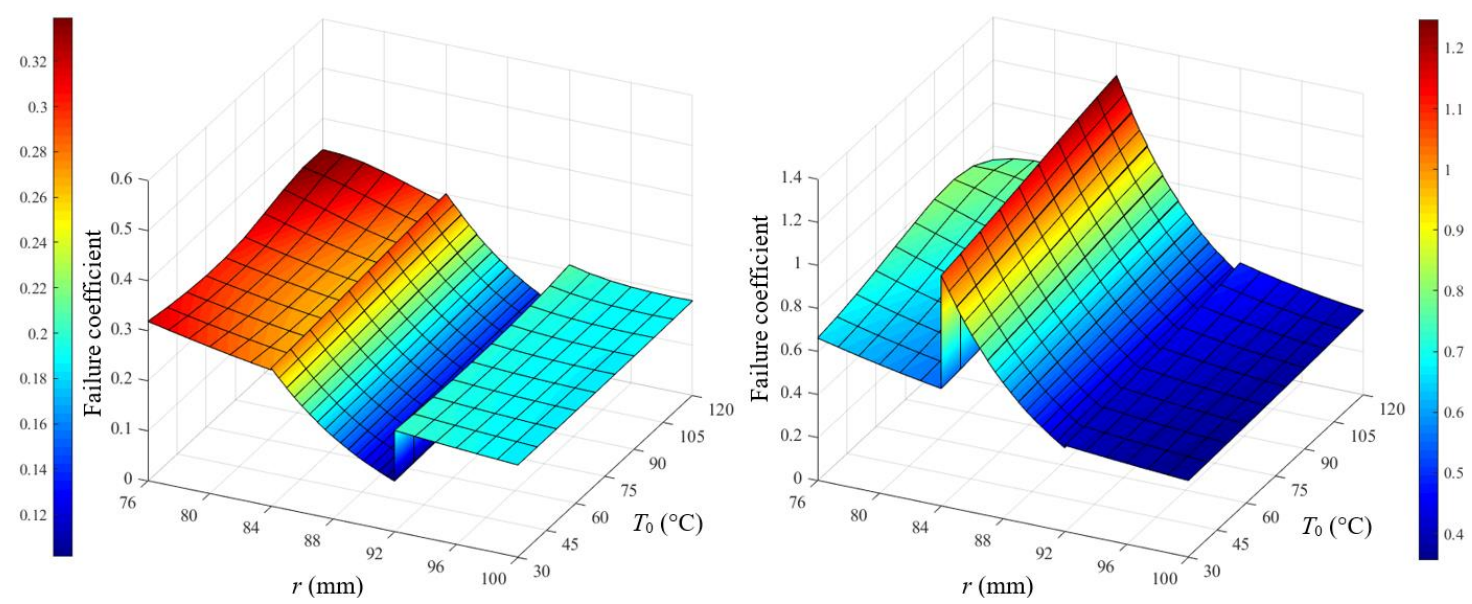

Figure 8. Effect of $T_{0}$ on failure coefficient for $P_{0} / P_{\mathrm{a}}=3: 45 / 15 \mathrm{MPa}$ (left); $90 / 30 \mathrm{MPa}$ (right)

\subsection{Increasing axial load}

TCP failure distributions under 50,250 and $500 \mathrm{kN}$ axial tensions, $P_{0} / P_{\mathrm{a}}=30 / 15 \mathrm{MPa}$ and low and high thermal gradients are shown in Figure 9. Increasing tension results in a uniform increase in laminate failure coefficient. At high tension the laminate exhibits larger coefficient than the inner liner, i.e. the laminate becomes the critical layer in the pipe. For the $T_{0}=30^{\circ} \mathrm{C}$ case the coefficient through both liners increases uniformly with tension. For $T_{0}=120^{\circ} \mathrm{C}$, the coefficient through the inner liner is lower at $250 \mathrm{kN}$ than at $50 \mathrm{kN}$. At $500 \mathrm{kN}$ tension the coefficient is more constant through the liner thickness. 

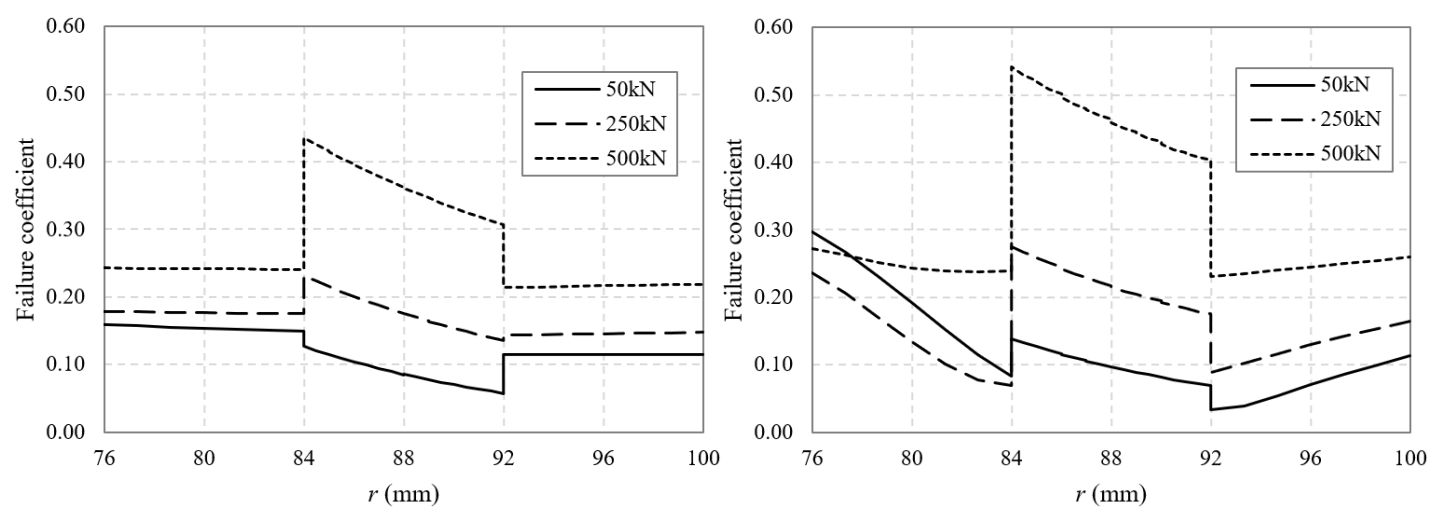

Figure 9. Effect of increasing $F_{\mathrm{A}}$ for $P_{0} / P_{\mathrm{a}}=30 / 15 \mathrm{MPa}: T_{0}=30^{\circ} \mathrm{C}$ (left); $T_{0}=120^{\circ} \mathrm{C}$ (right)

Failure distributions for 50, 250 and $500 \mathrm{kN}$ tensions at $P_{0} / P_{\mathrm{a}}=60 / 30 \mathrm{MPa}$ are shown in Figure 10 . Compared to the $P_{0} / P_{\mathrm{a}}=30 / 15 \mathrm{MPa}$ scenarios, the change in tension under the higher pressures has less effect on failure coefficient through the liners. As before, there is a uniform increase in the laminate coefficient at higher tension. The TCP considered here with $[ \pm 55]_{4}$ laminate would be expected to fail in the laminate under $500 \mathrm{kN}$ tension at $T_{0}=120^{\circ} \mathrm{C}$.
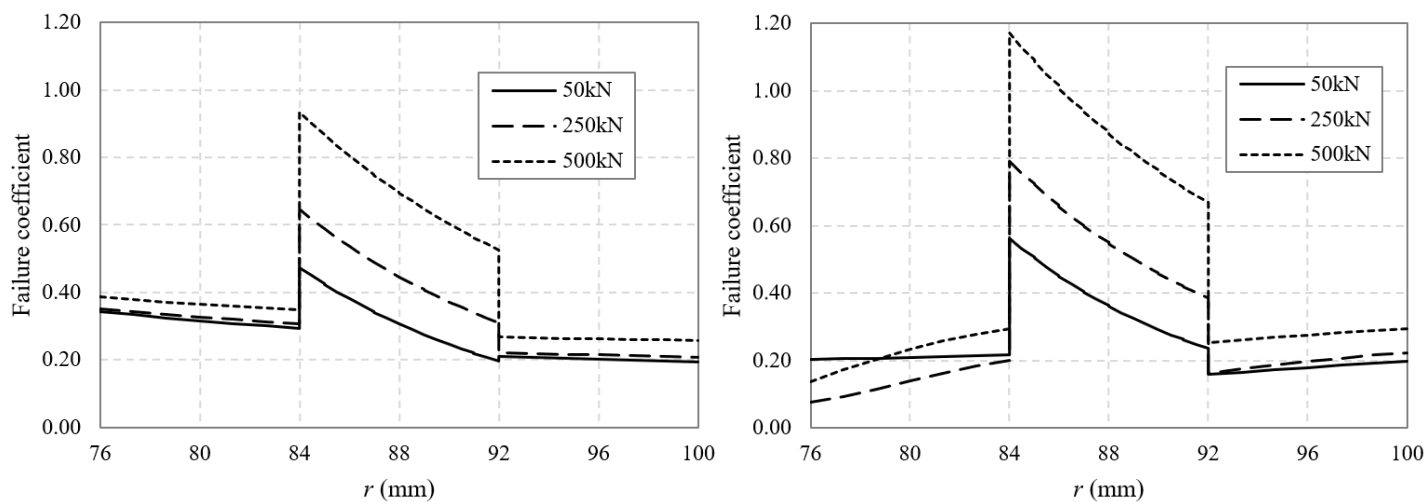

Figure 10. Effect of increasing $F_{\mathrm{A}}$ for $P_{0} / P_{\mathrm{a}}=60 / 30 \mathrm{MPa}: T_{0}=30^{\circ} \mathrm{C}$ (left); $T_{0}=120^{\circ} \mathrm{C}$ (right)

\subsection{Alternative laminate stacking sequences}

Figure 11 shows failure distributions for alternative TCP configurations with $\left[( \pm 30)_{2} /( \pm 55)_{2}\right]$ and $\left[( \pm 55)_{2} /( \pm 30)_{2}\right]$ laminates under 50,250 and $500 \mathrm{kN}$ tensions, $P_{0} / P_{\mathrm{a}}=30 / 15 \mathrm{MPa}$ and low and high thermal gradients. Through-liner coefficients are virtually identical for the two configurations. In the case of the $\left[( \pm 30)_{2} /( \pm 55)_{2}\right]$ configuration under both thermal gradients, the laminate coefficient only increases significantly through the $\pm 55^{\circ}$ plies. The maximum through-thickness failure coefficient for the laminate, and therefore practical safety factor, does not change with the increase in tension. Under all conditions the $\left[( \pm 55)_{2} /( \pm 30)_{2}\right]$ laminate exhibits lower coefficient than the counterpart. For this configuration there is a small rise in coefficient through the $\pm 30^{\circ}$ plies from 250 to $500 \mathrm{kN}$. Rising coefficient through the $\pm 55^{\circ}$ plies increases the maximum coefficient for the laminate. At $T_{0}=30^{\circ} \mathrm{C}$ the maximum failure coefficient for the TCP as a whole is thus increased at high tension, whereas for $T_{0}=120^{\circ} \mathrm{C}$ the laminate failure coefficient is always below that of the inner liner, even at $500 \mathrm{kN}$, and increasing tension does not alter the overall pipe safety factor if all layers are considered. 

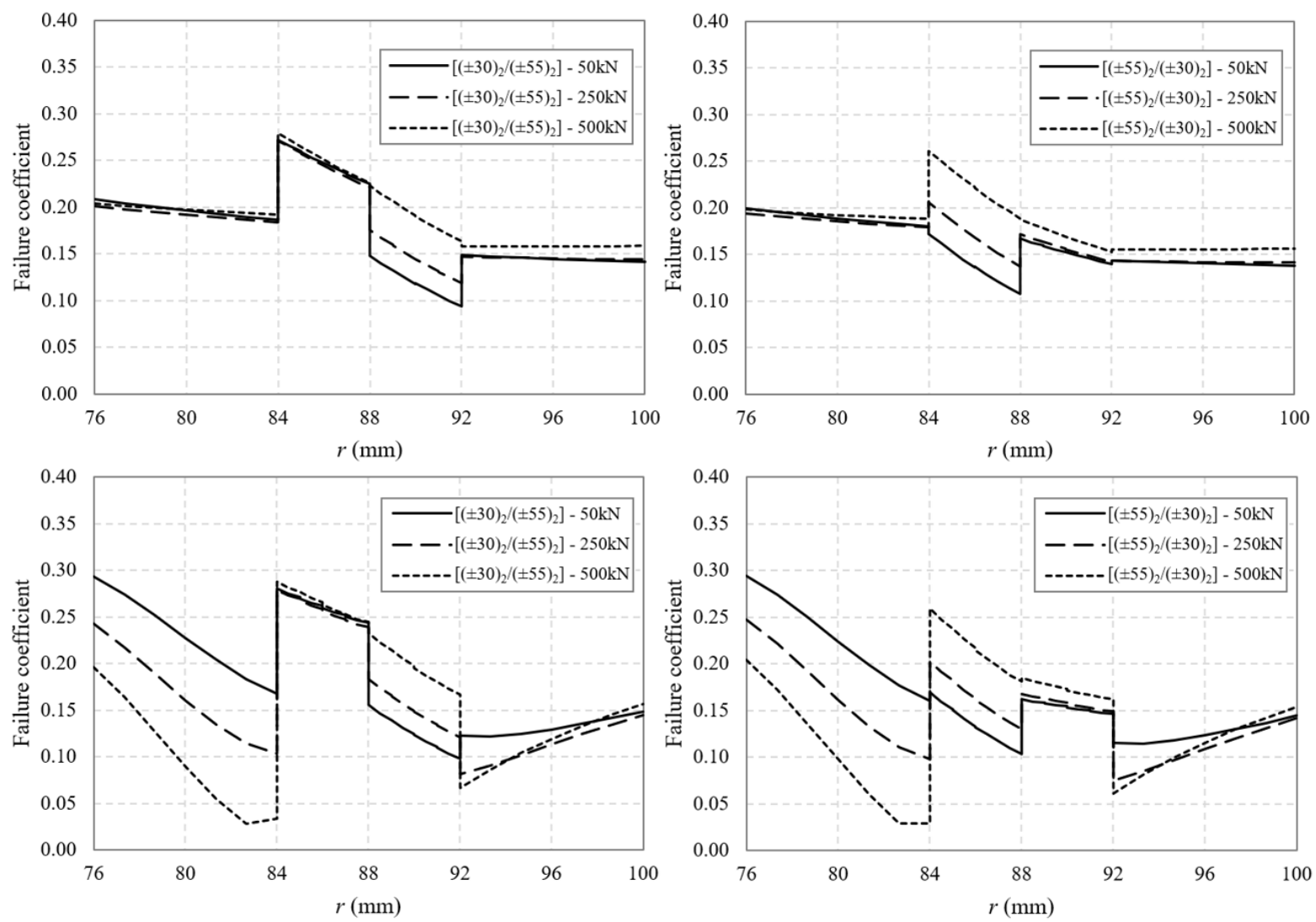

Figure 11. Effect of increasing $F_{\mathrm{A}}$ on failure distribution for alternative TCPs under $P_{0} / P_{\mathrm{a}}=30 / 15 \mathrm{MPa}: T_{0}$ $=30^{\circ} \mathrm{C}$ (top); $T_{0}=120^{\circ} \mathrm{C}$ (bottom)

Failure distributions for the alternative configurations under different tensions at $P_{0} / P_{\mathrm{a}}=$ $60 / 30 \mathrm{MPa}$ are shown in Figure 12. As was observed for the basic $[ \pm 55]_{4}$ TCP, the von Mises coefficient through the liners varies less with tension under higher pressures. The coefficient through the $\pm 30^{\circ}$ laminate plies does not change, regardless of whether the plies are wound on the inner or outer portion of the laminate. As before, the practical failure coefficient for the $\left[( \pm 30)_{2} /( \pm 55)_{2}\right]$ configuration, governed by the $\pm 30^{\circ}$ portion of the laminate, is the same for all scenarios and always higher than the $\left[( \pm 55)_{2} /( \pm 30)_{2}\right]$ coefficient. Compared to the original configuration with $[ \pm 55]_{4}$ laminate, the $\left[( \pm 55)_{2} /( \pm 30)_{2}\right]$ configuration is superior under high tension in terms of lower laminate failure coefficient.
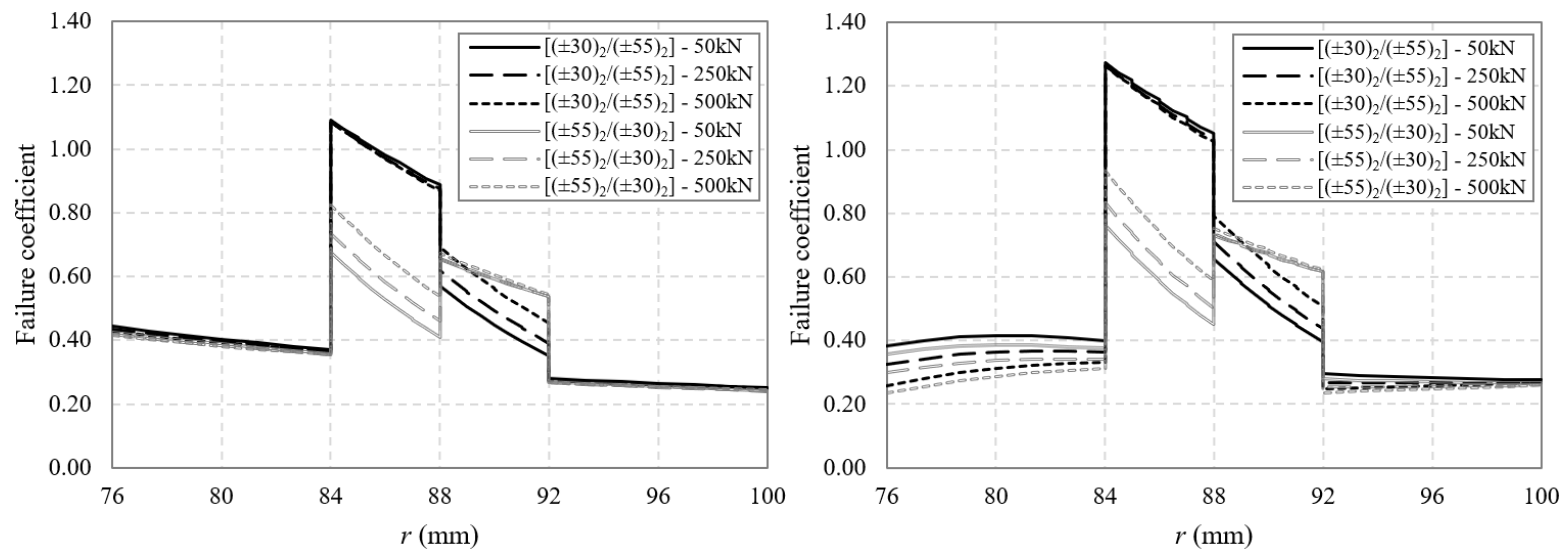

Figure 12. Effect of increasing $F_{\mathrm{A}}$ on failure distribution for alternative TCPs under $P_{0} / P_{\mathrm{a}}=60 / 30 \mathrm{MPa}: T_{0}$

$$
=30^{\circ} \mathrm{C} \text { (left); } T_{0}=120^{\circ} \mathrm{C} \text { (right) }
$$




\subsection{Discussion}

During its service life, the internal surface temperature of a riser will fluctuate with different operations. Increasing $T_{0}$ causes significant variation in the von Mises coefficient through the inner liner at low equal pressures and low internal-to-external pressure differential. At higher pressures the effects of increasing $T_{0}$ on the liner response are less severe. In practical terms, safety factors for the inner liner will vary considerably depending on the temperature of the internal pipe fluid in low pressure applications. In high pressure scenarios (i.e. greater ocean depth), safety factors will vary less with changing internal temperature, which may afford greater flexibility of operations. Utilisation of the balanced $[ \pm 55]_{4}$ laminate studied here was greater under higher pressures and the laminate became the critical layer in the pipe.

Increasing the TCP axial tension results in a uniform rise in Tsai-Hill coefficient through the thickness of the balanced $[ \pm 55]_{4}$ laminate. As with pressure, high tension will cause the overall maximum coefficient for the TCP to switch from the inner liner to the laminate and varying the tension has less effect on the liner under higher pressures. For high tension scenarios it is beneficial to orientate a portion of the outermost laminate plies at a low angle. The configuration with $\left[( \pm 55)_{2} /( \pm 30)_{2}\right]$ laminate is superior to the counterpart with $\left[( \pm 30)_{2} /( \pm 55)_{2}\right]$ laminate in terms of lower Tsai-Hill coefficient under all conditions studied here. However, higher tension is accompanied by increased maximum coefficient for the $\left[( \pm 55)_{2} /( \pm 30)_{2}\right]$ laminate, whereas the maximum for the opposite laminate did not change with tension, i.e. the safety factor would stay the same. For low tension scenarios it is not beneficial to include low angle plies, as the basic $[ \pm 55]_{4}$ TCP exhibited lower laminate and liner failure coefficients under low and high pressure/temperature differentials.

\section{Conclusions}

In the present paper, a 3D FE model capable of predicting stress state in a section of TCP under combined pressure, axial tension and thermal gradient was used to investigate through-thickness failure distribution for TCP operating in illustrative SLHR scenarios. Global riser analysis tools can be used to determine the inputs for the FE model used here, i.e. for global-local analysis.

Failure distributions based on von Mises criterion for isotropic liners and interactive Tsai-Hill for fibre-reinforced laminate were analysed for different combinations of pressure and thermal gradients. For real world design and application of TCP it is crucial that mechanical and thermal loads are considered in combination. Under low pressures, increasing the internal temperature causes a drastic rise in the inner liner failure coefficient. The through-liner coefficient is more stable and the structural laminate becomes the critical layer in the pipe under higher pressures. In practical terms, failure predictions will fluctuate less with changing thermal gradients over the service life of the TCP riser if operating under higher pressures. This may afford the designer a wider range of internal fluid temperatures.

Failure response under different axial tensions at low/high pressures and thermal gradients was analysed. Increasing tension results in a uniform increase in failure coefficient through laminate plies orientated at $\pm 55^{\circ}$. Changes in liner failure coefficient with tension are more pronounced at lower pressures. Two alternative TCP configurations with $\left[( \pm 30)_{2} /( \pm 55)_{2}\right]$ and $\left[( \pm 55)_{2} /( \pm 30)_{2}\right]$ laminates were investigated under different tensions and pressures at low and high thermal gradients. For high tension scenarios a lower laminate failure coefficient can be achieved by orientating outer laminate plies at a low fibre angle. 


\section{References}

[1] Guz, I.A., Menshykova, M., Paik, J.K., 2017. Thick-walled composite tubes for offshore applications: an example of stress and failure analysis for filament-wound multi-layered pipes. Ships and Offshore Structures 12 (3), 304-322.

[2] DNV, 2010. Recommended Practice DNV-RP-F202 Composite Risers.

[3] DNV, 2013. Offshore Standard DNV-OS-C501 Composite Components.

[4] DNV GL, 2015. Recommended Practice DNVGL-RP-F119 Thermoplastic Composite Pipes.

[5] Menshykova, M., Guz, I.A., 2014. Stress analysis of layered thick-walled composite pipes subjected to bending loading. International Journal of Mechanical Sciences 88, 289-299.

[6] Cox, K., Menshykova, M., Menshykov, O., Guz, I., 2019. Analysis of flexible composites for coiled tubing applications. Composite Structures 225, 111118.

[7] Xu, Y., Bai, Y., Fang, P., Yuan, S., Liu, C., 2019. Structural analysis of fibreglass reinforced bonded flexible pipe subjected to tension. Ships and Offshore Structures, 1-11.

[8] Knapp, R.H., 1975. Nonlinear analysis of a helically armored cable with non-uniform mechanical properties in tension and torsion. Proceedings of the IEEE OCEAN 75 Conference; San Diego (CA). 155164.

[9] Knapp, R.H., 1979. Derivation of a new stiffness matrix for helically armoured cables considering tension and torsion. International Journal for Numerical Methods in Engineering 14 (4), 515-529.

[10] Qiao, H., Zhang, Y., Bai, Y., Cheng, P., Lu, Y., Han, P., Tang, G., 2018. Study on reinforced thermoplastic pipe under combined tension and internal pressure. Ships and Offshore Structures 13 (sup1), S86-S97.

[11] Bai, Y., Yu, B., Cheng, P., Wang, N., Ruan, W., Tang, J., Babapour, A., 2015. Bending Behavior of Reinforced Thermoplastic Pipe. Journal of Offshore Mechanics and Arctic Engineering 137 (2), 021701.

[12] Bai, Y., Tang, J., Xu, W., Cao, Y., Wang, R., 2015. Collapse of reinforced thermoplastic pipe (RTP) under combined external pressure and bending moment. Ocean Engineering 94, 10-18.

[13] Cao, Y., Yu, X., Liu, Z., Bai, Y., Gong, X., 2017. On critical design parameters of reinforced thermoplastic pipes associated with the pipe-lay installation. Ships and Offshore Structures 12 (sup1), S134-S143.

[14] Yu, K., Morozov, E.V., Ashraf, M.A., Shankar, K., 2017. A review of the design and analysis of reinforced thermoplastic pipes for offshore applications. Journal of Reinforced Plastics and Composites 36 (20), 1514-1530.

[15] Bai, Y., Chen, W., Xiong, H., Qiao, H., Yan, H., 2016. Analysis of steel strip reinforced thermoplastic pipe under internal pressure. Ships and Offshore Structures 11 (7), 766-773. 
[16] Bai, Y., Liu, T., Cheng, P., Yuan, S., Yao, D., Tang, G., 2016. Buckling stability of steel strip reinforced thermoplastic pipe subjected to external pressure. Composite Structures 152, 528-537.

[17] Zhang, Q., Wang, Z.W., Tang, C.Y., Hu, D.P., Liu, P.Q., Xia, L.Z., 2012. Analytical solution of the thermo-mechanical stresses in a multilayered composite pressure vessel considering the influence of the closed ends. International Journal of Pressure Vessels and Piping 98, 102-110.

[18] Bakaiyan, H., Hosseini, H., Ameri, E., 2009. Analysis of multi-layered filament-wound composite pipes under combined internal pressure and thermomechanical loading with thermal variations. Composite Structures 88 (4), 532-541.

[19] Kayhani, M.H., Norouzi, M., Amiri Delouei, A., 2012. A general analytical solution for heat conduction in cylindrical multilayer composite laminates. International Journal of Thermal Sciences 52, $73-82$.

[20] Xia, M., Kemmochi, K., Takayanagi, H., 2001. Analysis of filament-wound fiber-reinforced sandwich pipe under combined internal pressure and thermomechanical loading. Composite Structures 51 (3), 273-283.

[21] Hastie, J.C., Guz, I.A., Kashtalyan, M., 2019. Effects of thermal gradient on failure of a thermoplastic composite pipe (TCP) riser leg. International Journal of Pressure Vessels and Piping, 172, 90-99.

[22] Xia, M., Takayanagi, H., Kemmochi, K., 2001. Analysis of multi-layered filament-wound composite pipes under internal pressure. Composite Structures 53 (4), 483-491.

[23] Herakovich, C.T., 1998. Mechanics of fibrous composites. New York (NY): Wiley.

[24] Cytec, 2012. APC-2 PEEK thermoplastic polymer technical data sheet. 